\title{
Abdominal obesity phenotype is associated with COVID-19 chest X-ray severity score better than BMI-based obesity
}

\author{
Alexis Elias Malavazos ${ }^{1}\left(\right.$ Francesco Secchi $^{2,3} \cdot$ Sara Basilico $^{1,4} \cdot$ Gloria Capitanio $^{1} \cdot$ Sara Boveri $^{5} \cdot$ Valentina Milani $^{5}$. \\ Carola Dubini ${ }^{1}$. Simone Schiaffino ${ }^{2} \cdot$ Lelio Morricone $^{1} \cdot$ Chiara Foschini $^{2} \cdot$ Giulia Gobbo $^{6} \cdot$ Rosangela Piccinni $^{6}$. \\ Alessandro Saibene ${ }^{7}$. Francesco Sardanelli ${ }^{2,3} \cdot$ Lorenzo Menicanti $^{5} \cdot$ Marco Guazzi $i^{3,8}$. Chuanhui Dong ${ }^{9}$. \\ Massimiliano Marco Corsi Romanelli $i^{3,10}$. Michele Carruba ${ }^{11}$. Gianluca lacobellis ${ }^{12}$
}

Received: 26 January 2021 / Revised: 11 March 2021 / Accepted: 16 March 2021 / Published online: 5 April 2021

(C) The Author(s), under exclusive licence to Springer Nature Switzerland AG 2021

\begin{abstract}
Purpose Chest X-ray (CXR) severity score and BMI-based obesity are predictive risk factors for COVID-19 hospital admission. However, the relationship between abdominal obesity and CXR severity score has not yet been fully explored.

Methods This retrospective cohort study analyzed the association of different adiposity indexes, including waist circumference and body mass index (BMI), with CXR severity score in 215 hospitalized patients with COVID-19.

Results Patients with abdominal obesity showed significantly higher CXR severity scores and had higher rates of CXR severity scores $\geq 8$ compared to those without abdominal obesity $(P<0.001 ; P=0.001$, respectively). By contrast, patients with normal weight, with overweight and those with BMI-based obesity showed no significant differences in either CXR severity scores or in the rates of CXR severity scores $\geq 8(P=0.104 ; P=0.271$, respectively). Waist circumference and waistto-height ratio (WHtR) correlated more closely with CXR severity scores than BMI $(r=0.43, P<0.001 ; r=0.41, P<0.001$; $r=0.17, P=0.012$, respectively). The area under the curves (AUCs) for waist circumference and WHtR were significantly higher than that for BMI in identifying a high CXR severity score $(\geq 8)(0.68[0.60-0.75]$ and 0.67 [0.60-0.74] vs 0.58 [0.51-0.66], $P=0.001$ ). A multivariate analysis indicated abdominal obesity (risk ratio: $1.75,95 \%$ CI: $1.25-2.45, P<0.001$ ), bronchial asthma (risk ratio: $1.73,95 \%$ CI: $1.07-2.81, P=0.026$ ) and oxygen saturation at admission (risk ratio: $0.96,95 \%$ CI: $0.94-0.97, P<0.001)$ as the only independent factors associated with high CXR severity scores.

Conclusion Abdominal obesity phenotype is associated with a high CXR severity score better than BMI-based obesity in hospitalized patients with COVID-19. Therefore, when visiting the patient in a hospital setting, waist circumference should be measured, and patients with abdominal obesity should be monitored closely.

Level of evidence Cross-sectional descriptive study, Level V.
\end{abstract}

Keywords COVID-19 · Abdominal Obesity · Body Mass Index · Visceral Obesity $\cdot$ Chest X-Ray $\cdot$ Interleukin 6

\section{Introduction}

Coronavirus disease 2019 (COVID-19), the infectious disease caused by the novel severe acute respiratory syndrome coronavirus 2 (SARS-CoV-2), has a broad spectrum of clinical presentations, from asymptomatic infection to influenza-like symptoms all the way to severe pneumonia, leading then to acute respiratory distress syndrome (ARDS) [1]. Early identification of individual phenotypes is essential

Alexis Elias Malavazos

alexis.malavazos@gmail.com

Extended author information available on the last page of the article in patients who are particularly inclined to develop severe COVID-19 and who may need hospital admission. Older patients and those with pre-existing non-communicable diseases (NCDs) seem more vulnerable to severe forms of COVID-19 [2].

Obesity is a gateway to many NCDs, and people with BMI-based obesity seem to have a high risk of hospitalizations, serious illnesses, and mortality [3]. With the rising prevalence of obesity, awareness of its impact on communicable diseases has increased [4, 5]. During the 2009 A H1N1 influenza pandemic, obesity was identified as an independent risk factor for more severe disease and mortality in infected individuals [6]. Moreover, patients with obesity were likely 
to develop both upper and lower respiratory tract infections more frequently [7] and even hypoventilation-associated with pneumonia $[8,9]$.

Evidence is now emerging that obesity is also a risk factor in the current SARS-CoV-2 pandemic [10, 11]. A recent study found that COVID-19 becomes more severe as the body mass index (BMI) increases and that hospitalized male patients with obesity have a higher mortality rate and are more likely to require mechanical ventilation $[12,13]$, with most patients with BMI $>35$ requiring intubation $[14,15]$.

During the current SARS-CoV-2 pandemic, chest X-rays (CXR) have played a very important role in the early diagnosis and treatment of patients with suspected or confirmed COVID-19 chest infections. It has become the primary imaging tool for clinical management and severity stratification [16-18]. Although computed tomography (CT) is considered the most effective method for the detection of lung abnormalities, it is characterized by a lower specificity [19] and its routine use may be impractical especially when there is a large inflow of patients with suspected COVID-19 chest infections [16].

To improve the risk stratification for patients with acute respiratory infection, there are several CXR scoring systems which can be easily replicated in different clinical settings $[17,18,20,21]$. A high CXR severity score has been associated with in-hospital mortality of patients with COVID-19 [22]. It is worth noting that a high CXR severity score as well as a high BMI might be predictive risk factors for hospitalization and intubation in COVID-19 patients [17]. In addition, patients suffering from obesity have a higher risk of CXR severity due to COVID-19 pneumonia than patients with normal weight [23].

However, BMI is not always the best indicator of obesity because it does not account for the amount and distribution of body fat, which can vary markedly among people with the same BMI scores [24]. Location is the key when it comes to body fat.

People with obesity appear to present systemic lowgrade inflammation, higher susceptibility to infections due to a reduced immune response, and higher morbidity and mortality associated with infections [25-27]. The excess of abdominal visceral fat is considered the main culprit in inflammatory diseases linked to obesity and is an indicator of increased ectopic fat, which might increase atherosclerosis and raise cardiometabolic risk [28]. It has been recently suggested that excessive visceral adiposity may be related to the outcome of severe COVID-19 [29-33]. Patients in a large population-based cohort, with central obesity assessed by their waist circumference or waist-to-hip ratio (WHR), were also reported to be more likely to develop severe COVID-19 [34].

Detailed characterization of patients with COVID-19 pneumonia is essential to identify individuals or subgroups who are at increased levels of risk, and to be better prepared for disease progressions and outcomes.

However, further investigation into the role of abdominal adiposity distribution in the development and course of COVID-19 is still needed.

Therefore, the aim of this study was to find out whether abdominal obesity could better associate with CXR severity scores than BMI-based obesity in hospitalized COVID-19 patients.

\section{Methods}

\section{Study setting}

During the early stages of the COVID-19 pandemic, the Lombardy Health Care Service decided to use some hospitals in and around the city of Milan exclusively for the admission and care of COVID-19-positive patients. As the number of cases grew, our hospital, the IRCCS Policlinico San Donato, reacted swiftly by increasing the number of beds in the intensive care units (ICUs), and was then converted exclusively into a COVID-19 hub with all medical wards dedicated to COVID-19 patients.

\section{Study design}

This retrospective single-center study was approved by our Ethics Committee (Ethics Committee of San Raffaele Clinical Research Hospital; protocol code 37/int/2020). Specific informed consent was waived due to the retrospective nature of this study. The patients' confidentiality was protected by assigning them with anonymous identification codes. The study, conducted at the IRCCS Policlinico San Donato, was partially financed by the Italian Ministry of Health.

\section{Study population}

Through a review of the clinical and imaging database of the IRCCS Policlinico San Donato in San Donato Milanese, Italy, from March 9 to April 27, 2020, we identified data from 221 hospitalized patients with confirmed COVID-19 (by positive nasopharyngeal swab for RT-PCR) who underwent a CXR in the isolation rooms of the emergency department within a maximum time interval of $12 \mathrm{~h}$ and from whom anthropometric measurements (weight, height and waist circumference) were taken in the internal medicine and endocrinological-metabolic wards (Fig. 1). Patients with poor-quality images due to artifacts $(n=6)$ were excluded. Finally, a total of 215 patients affected by COVID-19 with optimal CXR images were included in this study. For patients with multiple CXR examinations, 


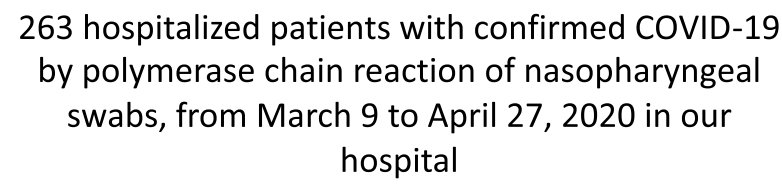

263 hospitalized patients with confirmed COVID-19 by polymerase chain reaction of nasopharyngeal swabs, from March 9 to April 27, 2020 in our hospital

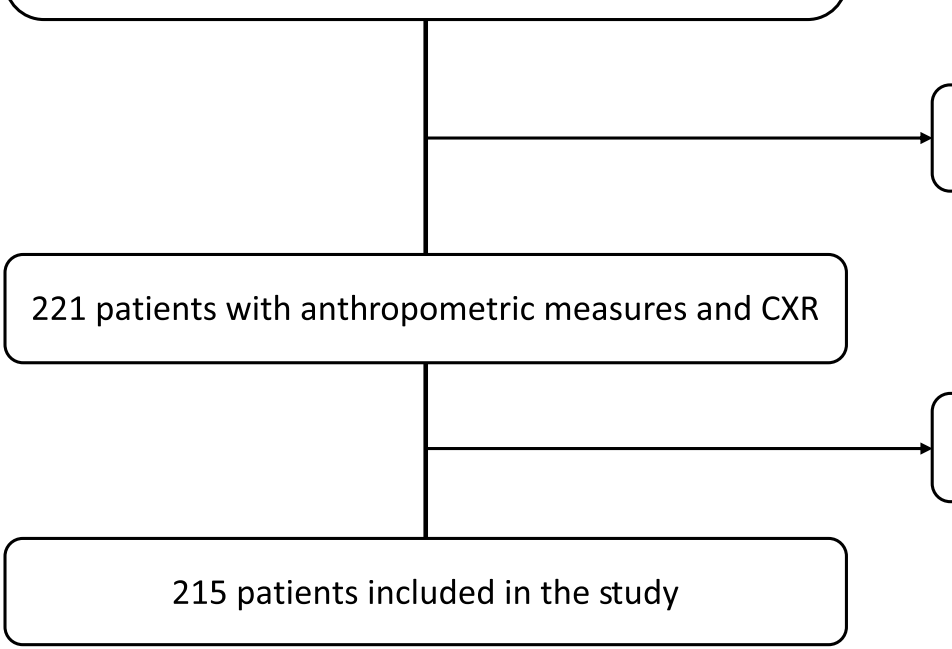

Patients without anthropometric measures and/or CXR $(n=42)$

Fig. 1 Flowchart for inclusion and exclusion criteria of our cohort. Chest X-ray (CXR). The figure was created by an author (S.B.) using the program Microsoft Power Point

the CXR with the shortest time interval between imaging and symptom onset was used for this analysis.

\section{Data collection}

Upon admission to our ward, each patient's demographic, anthropometric and clinical history datum was added to the hospital's electronic clinical database, and all clinical data were updated daily during the entire hospital stay. We extracted the following data for this study: gender, age, race, height, weight, waist circumference, pre-existing comorbidities and clinical outcomes. Values of inflammatory biochemical data of interleukin 6 (IL-6), oxygen saturation at admission $\left(\mathrm{SpO}_{2}\right)$ and oxygen therapy which were closest in time to the CXR were also collected. Patients were then classified according to waist circumference thresholds: those with abdominal obesity (waist circumference $\geq 102 \mathrm{~cm}$ for males, $\geq 88 \mathrm{~cm}$ for females) and those without abdominal obesity (waist circumference $<102 \mathrm{~cm}$ for males, $<88 \mathrm{~cm}$ for females) [35]. According to the CDC definition [36], patients were also classified on the basis of their BMI as: with underweight (less than $18.5 \mathrm{~kg}$ / $\mathrm{m}^{2}$ ), with normal weight ( 18 to $<25 \mathrm{~kg} / \mathrm{m}^{2}$ ), with overweight $\left(25\right.$ to $\left.<30 \mathrm{~kg} / \mathrm{m}^{2}\right)$ and with obesity $\left(\geq 30 \mathrm{~kg} / \mathrm{m}^{2}\right)$.

\section{Anthropometric measurements}

Anthropometric measurements were taken upon admission to the internal medicine and endocrinological-metabolic wards, with patients wearing light indoor clothing and no shoes. All the anthropometric measurements were taken with the assistance of the nursing staff. The standing height was measured to the nearest $0.1 \mathrm{~cm}$ and weight to the nearest $0.1 \mathrm{~kg}$ using a scale with a stadiometer. The waist circumference was measured at the umbilicus three times using an extensible tape measure and the average of the three was recorded. Waist-to-height ratio (WHtR) was calculated as the waist circumference divided by the height, in centimeters. BMI was calculated as weight (kilograms) divided by height (meters) squared.

\section{CXR examination}

All CXRs were taken at the bedside in the emergency department (ED) isolation rooms, using one of two different CXR systems (Digital GM85, Samsung Healthcare, Seoul, South Korea; Digital FDR Go PLUS, Fujifilm, Tokyo, Japan). Two radiologists (F.S. and S.S., with, respectively, 15 and 7 years of experience in chest imaging) independently and blindly reviewed all anonymized 
CXRs. In the case of any discordance, agreement was reached on how to rate the pulmonary parenchyma. The inter-observer agreement on the CXR severity scores by the two radiologists was excellent (ICC 0.995).

\section{CXR severity score}

The readers rated pulmonary parenchymal involvement using a semi-quantitative severity score already validated for COVID-19 pneumonia assessment [21, 37]. First, the lungs were divided into six zones (three per lung) on frontal chest projection: the upper zone (from the lung apex to the aortic arch profile), the middle zone (lung hilum, from the aortic arch profile to the lower margin of the lower pulmonary vein), the lower zone (from the lower margin of the lower pulmonary vein to the diaphragm), Fig. 2. CXR was classified with a severity scale expressed as a continuous variable. For each zone, a score of 0-3 in 1-point increments was assigned: 0, normal lung parenchyma; 1 , interstitial involvement only; 2 , radiopacity of less than $50 \%$ of the visible lung parenchyma; 3 , radiopacity of $50 \%$ or more of the visible lung parenchyma (Fig. 3). The scores of the six lung zones were then added together to obtain an overall CXR score ranging from 0 to 18 . In our population, CXR severity scores ranged from 0 to 17 .

\section{High CXR severity score}

A CXR severity score of 8 or more was associated with the involvement of at least four out of six lung segments (corresponding to $67 \%$ of lung involvement). The optimal cutoff value of 8 points has been recently associated with poor prognosis in patients with COVID-19 [22]. For this reason, we used a cut-off of 8 to indicate a high CXR severity score. This enabled the clinical staff to stratify the patients' risks very quickly.

\section{Oxygen therapy}

The need for and invasiveness of oxygen therapy, within $12 \mathrm{~h}$ after hospitalization, were rated as follows: mild, when the patient did not require $\mathrm{O}_{2}$; moderate when the patient required $\mathrm{O}_{2}$; severe when the patient required non-invasive ventilator support (continuous positive airway pressure, CPAP) but was not intubated; critical when the patient required intubation.

\section{Pre-existing comorbidities}

Pre-existing comorbidities, such as hypertension, diabetes mellitus, ischemic cardiomyopathy, atrial fibrillation, chronic obstructive pulmonary disease, chronic kidney failure, bronchial asthma, or chronic heart failure, were
Fig. 2 An example of a chest $\mathrm{X}$-ray. Chest X-ray (CXR); Right (R); Antero-posterior (AP). Each CXR was divided into three parts for each lung: upper zone (from the lung apex to the aortic arch profile), middle zone (lung hilum, from the aortic arch profile to the inferior margin of the inferior pulmonary vein), and lower zone (from the inferior margin of the inferior pulmonary vein to the diaphragm)

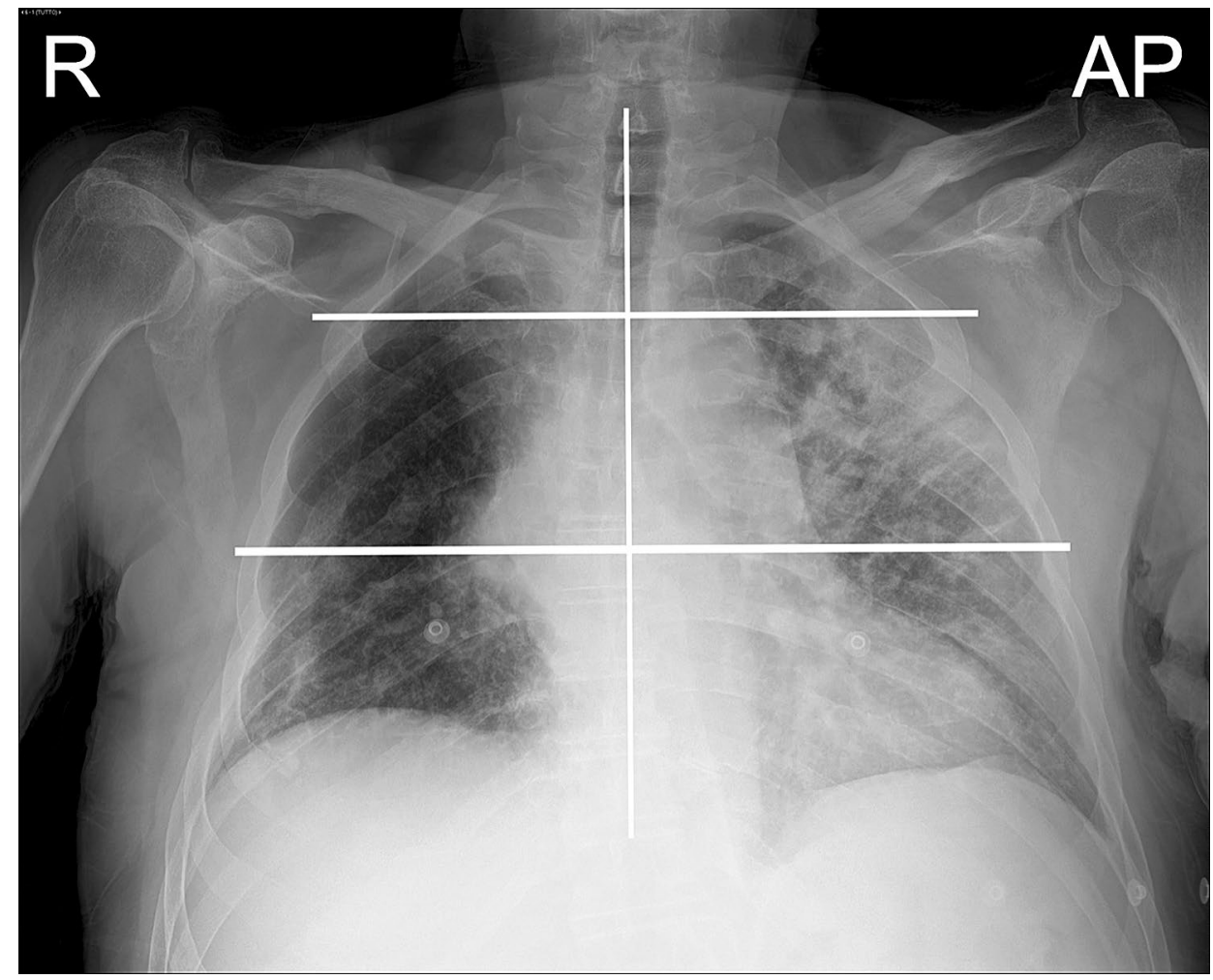




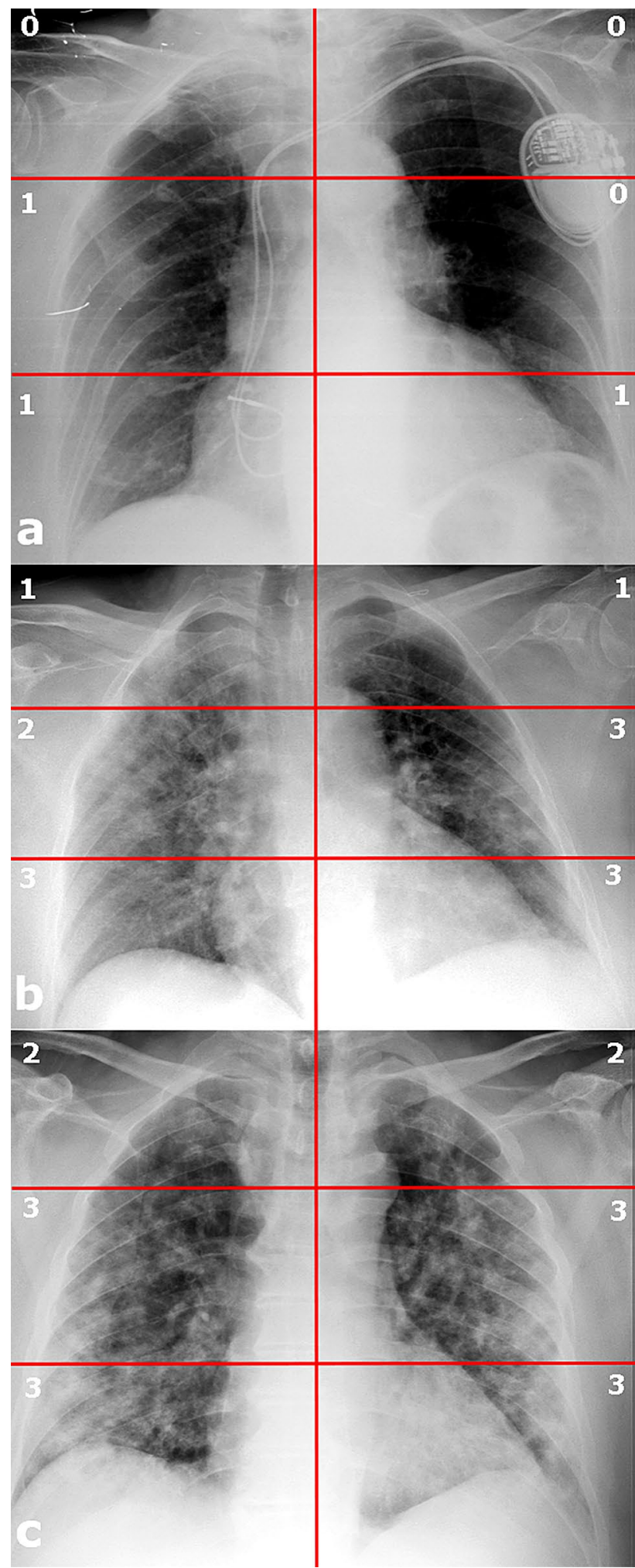

Fig. 3 Three chest X-rays in COVID-19 patients with different lung parenchyma disease grades. Chest X-ray (CXR). a CXR severity score 3; b CXR severity score 13; c CXR severity score 16 identified from the patients' clinical history and electronic medical records.

\section{Statistical analysis}

Categorial variables were described as frequency and percentages, and continuous variables as a mean $\pm \mathrm{SD}$ or median and interquartile range (IQR), as appropriate. The means for continuous variables were compared using independent group t-tests when the data were normally distributed, otherwise the Mann-Whitney test was applied. Categorial variables were compared using the $\chi^{2}$ test or Fisher's exact test. Correlations between continuous variables were evaluated according to Spearman Rho. To evaluate the accuracy of waist circumference, the $\mathrm{WHtR}$ and $\mathrm{BMI}$ in relation to a high CXR severity score, receiver operating characteristic (ROC) curves were used. The area under the curve (AUC) was taken as the summary discrimination measure. The AUCs were compared with the method of DeLong et al. [38].

We used Poisson regression models with a robust error variance [39] to identify the clinical determinants (with univariate $p<0.1$ and forcing age into the model), independently associated with a high CXR severity score $(\geq 8)$, using risk ratios (RR) and 95\% confidence intervals (CI). The analyses included continuous variables (age, IL- 6 and $\mathrm{SpO}_{2}$ ) and categorial variables (gender, race, smoking, abdominal obesity, BMI-based obesity, and comorbidities).

All statistical tests were two-sided. $p<0.05$ was considered significant. All analyses were made with SAS 9.4 (SAS Institute Inc., Cary, NC, USA).

\section{Results}

\section{Clinical characteristics of patients, based on different adiposity indexes}

We classified our study population according to different adiposity indexes, adopting waist circumference as an indicator of abdominal fat distribution and BMI as an indicator of general fatness. The clinical characteristics of patients with and without abdominal obesity or with normal weight, with overweight and with BMI-based obesity are shown in Table 1. No patient was underweight and only $6.5 \%(n=14)$ had a BMI of between 35 and $40 \mathrm{~kg} / \mathrm{m}^{2}$, while $1.4 \%(n=3)$ had a BMI over $40 \mathrm{~kg} / \mathrm{m}^{2}$. In the overall population, CXR severity scores ranged from 0 to 17 and $48 \%(n=103)$ of patients had a high CXR severity score $(\geq 8)$. Patients with abdominal obesity had significantly higher CXR severity scores (Fig. 4a) and higher rates of CXR severity scores $\geq 8$ than those without abdominal obesity $(P<0.001 ; P=0.001$, respectively) (Table 1$)$, 
Table 1 Clinical characteristics of patients with COVID-19 based on adiposity indexes

\begin{tabular}{|c|c|c|c|c|c|c|c|c|}
\hline & \multirow[t]{2}{*}{ Total (215) } & \multicolumn{3}{|c|}{ Abdominal obesity } & \multicolumn{4}{|l|}{ BMI classes } \\
\hline & & No $102(47 \%)$ & Yes $113(53 \%)$ & $p$-value & $\begin{array}{l}\text { Normal } \\
\text { weight } n=74 \text {, } \\
(34 \%)\end{array}$ & $\begin{array}{l}\text { Overweight } \\
n=87 \\
(41 \%)\end{array}$ & Obesity $n=54,(25 \%)$ & $p$-value \\
\hline \multicolumn{9}{|c|}{ Demographic information } \\
\hline Age, years ${ }^{a}$, no. (\%) & $62.7 \pm 14.05$ & $61.6 \pm 15.0$ & $63.7 \pm 13.1$ & 0.275 & $63.6 \pm 14.8$ & $63.9 \pm 13.7$ & $59.6 \pm 13.4$ & 0.169 \\
\hline$<40$ & $12(6)$ & $9(9)$ & $3(3)$ & & $5(7)$ & $5(6)$ & $2(4)$ & \\
\hline$(40-50]$ & $26(12)$ & $13(13)$ & $13(11)$ & & $8(11)$ & $7(8)$ & $11(20)$ & \\
\hline$(50-60]$ & $57(26)$ & $25(24)$ & $32(28)$ & & $15(20)$ & $22(25)$ & $20(37)$ & \\
\hline$(60-70]$ & $49(23)$ & $22(22)$ & $27(24)$ & & $20(27)$ & $22(25)$ & $7(13)$ & \\
\hline$>70$ & $71(33)$ & $33(32)$ & $38(34)$ & & $26(35)$ & $31(36)$ & $14(26)$ & \\
\hline Gender, no. (\%) & & & & 0.129 & & & & 0.001 \\
\hline Male & $145(67)$ & $74(73)$ & $71(63)$ & & $38(51)$ & $65(75)$ & $42(78)$ & \\
\hline Female & $70(33)$ & $28(27)$ & $42(37)$ & & $36(49)$ & $22(25)$ & $12(22)$ & \\
\hline Race, no. (\%) & & & & $0.132 *$ & & & & $0.909^{*}$ \\
\hline Caucasian & $191(89)$ & $92(90)$ & $99(88)$ & & $66(89)$ & $77(89)$ & $48(89)$ & \\
\hline Latin-American & $12(6)$ & $4(4)$ & $8(7)$ & & $3(4)$ & $5(6)$ & $4(7)$ & \\
\hline African & $4(2)$ & $0(0)$ & $4(3)$ & & $1(1)$ & $2(2)$ & $1(2)$ & \\
\hline Asian & $4(2)$ & $3(3)$ & $1(1)$ & & $3(4)$ & $1(1)$ & $0(0)$ & \\
\hline Arabic & $4(2)$ & $3(3)$ & $1(1)$ & & $1(1)$ & $2(2)$ & $1(2)$ & \\
\hline Smoke, no. (\%) & & & & $0.648^{*}$ & & & & $0.932 *$ \\
\hline Current smoker & $28(13)$ & $12(12)$ & $16(14)$ & & $9(12)$ & $14(16)$ & $5(9)$ & \\
\hline Former smoker & $4(2)$ & $1(1)$ & $3(3)$ & & $1(1)$ & $2(2)$ & $1(1)$ & \\
\hline Never smoked & $147(68)$ & $71(70)$ & $76(67)$ & & $51(69)$ & $61(70)$ & $35(64)$ & \\
\hline NA & $36(17)$ & $18(17)$ & $18(16)$ & & $13(18)$ & $10(12)$ & $13(24)$ & \\
\hline \multicolumn{9}{|c|}{ Anthropometric measurements } \\
\hline Weight $(\mathrm{kg})^{\mathrm{a}}$ & $79.6 \pm 16.6$ & $71.5 \pm 12.7$ & $86.9 \pm 16.4$ & $<0.001$ & $64.5 \pm 9.5$ & $80.7 \pm 8.9$ & $98.5 \pm 13.4$ & $<0.001$ \\
\hline Height $(\mathrm{cm})^{\mathrm{a}}$ & $170.0 \pm 10.0$ & $169 \pm 10$ & $170 \pm 10$ & 0.379 & $169 \pm 10$ & $171 \pm 10$ & $169 \pm 10$ & 0.335 \\
\hline Waist $(\mathrm{cm})^{\mathrm{a}}$ & $99.7 \pm 13.4$ & $89.4 \pm 9.2$ & $109.0 \pm 9.1$ & $<0.001$ & $88.2 \pm 10.8$ & $101.5 \pm 8.4$ & $112.4 \pm 10.0$ & $<0.001$ \\
\hline Waist male $(\mathrm{cm})^{\mathrm{a}}$ & $103.0 \pm 12.1$ & $93.3 \pm 7.2$ & $112.3 \pm 7.6$ & $<0.001$ & $91.7 \pm 10.1$ & $102 \pm 7.3$ & $113.3 \pm 10.4$ & $<0.001$ \\
\hline Waist female $(\mathrm{cm})^{\mathrm{a}}$ & $93.7 \pm 14.2$ & $79.1 \pm 5.3$ & $103.4 \pm 8.9$ & $<0.001$ & $84.5 \pm 10.3$ & $100.0 \pm 11.2$ & $109.4 \pm 7.9$ & $<0.001$ \\
\hline $\mathrm{WHtR}^{\mathrm{a}}$ & $0.6 \pm 0.1$ & $0.5 \pm 0.1$ & $0.6 \pm 0.1$ & $<0.001$ & $0.5 \pm 0.06$ & $0.6 \pm 0.05$ & $0.7 \pm 0.1$ & $<0.001$ \\
\hline BMI $\left(\mathrm{kg} / \mathrm{m}^{2}\right)^{\mathrm{a}}$ & $27.5 \pm 4.9$ & $24.9 \pm 3.7$ & $29.8 \pm 4.7$ & $<0.001$ & $22.6 \pm 1.8$ & $27.5 \pm 1.3$ & $34.0 \pm 3.5$ & $<0.001$ \\
\hline \multicolumn{9}{|l|}{ Adiposity status } \\
\hline $\begin{array}{l}\text { Abdominal obesity, } \\
\text { no. }(\%)\end{array}$ & & & & & & & & $<0.001$ \\
\hline Yes & $113(53)$ & - & - & - & $17(23)$ & $49(56)$ & $47(87)$ & \\
\hline No & $102(47)$ & - & - & - & $57(77)$ & $38(44)$ & $7(13)$ & \\
\hline BMI classes, no. (\%) & & & & $<0.001$ & & & & \\
\hline Normal weight & $74(34)$ & $57(56)$ & $17(15)$ & & - & - & - & - \\
\hline Overweight & $87(41)$ & $38(37)$ & $49(43)$ & & - & - & - & - \\
\hline General obesity & $54(25)$ & $7(7)$ & $47(42)$ & & - & - & - & - \\
\hline \multicolumn{9}{|c|}{ Comorbidities, no. (\%) } \\
\hline Hypertension & $87(41)$ & $40(39)$ & $47(42)$ & 0.751 & $19(26)$ & $41(47)$ & $27(50)$ & 0.001 \\
\hline Diabetes mellitus & $31(14)$ & $10(10)$ & $21(19)$ & 0.067 & $7(9)$ & $15(17)$ & $9(17)$ & 0.320 \\
\hline $\begin{array}{l}\text { Ischemic cardiomyo- } \\
\text { pathy }\end{array}$ & $16(7)$ & $9(9)$ & $7(6)$ & 0.447 & $4(5)$ & $9(10)$ & $3(5)$ & 0.570 \\
\hline Atrial fibrillation & $13(6)$ & $7(7)$ & $6(5)$ & 0.646 & $5(7)$ & $7(8)$ & $1(2)$ & $0.459^{*}$ \\
\hline $\begin{array}{l}\text { Chronic Obstructive } \\
\text { Pulmonary Disease }\end{array}$ & $10(5)$ & $5(5)$ & $5(4)$ & $1.000^{*}$ & $4(5)$ & $4(5)$ & $2(1)$ & $0.9179^{*}$ \\
\hline $\begin{array}{l}\text { Chronic Kidney } \\
\text { Failure }\end{array}$ & $8(4)$ & $5(5)$ & $3(2)$ & $0.478 *$ & $3(4)$ & $2(2)$ & $3(5)$ & $0.465^{*}$ \\
\hline
\end{tabular}


Table 1 (continued)

\begin{tabular}{|c|c|c|c|c|c|c|c|c|}
\hline & \multirow[t]{2}{*}{ Total (215) } & \multicolumn{3}{|c|}{ Abdominal obesity } & \multicolumn{4}{|l|}{ BMI classes } \\
\hline & & No $102(47 \%)$ & Yes $113(53 \%)$ & $p$-value & $\begin{array}{l}\text { Normal } \\
\text { weight } n=74 \text {, } \\
(34 \%)\end{array}$ & $\begin{array}{l}\text { Overweight } \\
n=87 \\
(41 \%)\end{array}$ & Obesity $n=54,(25 \%)$ & $p$-value \\
\hline Bronchial asthma & $5(2)$ & $2(2)$ & $3(2)$ & $1.000^{*}$ & $1(1)$ & $4(5)$ & $0(0.0)$ & $0.295 *$ \\
\hline Chronic heart failure & $5(2)$ & $1(1)$ & $4(4)$ & 0.372 & $0(0.00)$ & $4(5)$ & $1(3)$ & 0.195 \\
\hline \multicolumn{9}{|c|}{ Clinical features, no. (\%) } \\
\hline \multicolumn{9}{|l|}{ Chest x-ray } \\
\hline $\begin{array}{l}\text { CXR severity } \\
\text { score }^{\text {b }}\end{array}$ & $7(4-10)$ & $6(3-9)$ & $9(6-11)$ & $<0.001$ & $7(3-10)$ & $7(5-10)$ & $9(5-11)$ & 0.104 \\
\hline $\begin{array}{l}\text { High CXR severity } \\
\text { score }(\geq 8), \text { no. } \\
(\%)\end{array}$ & $103(48)$ & $36(35)$ & $67(59)$ & 0.001 & $33(45)$ & $39(45)$ & $31(57)$ & 0.271 \\
\hline \multicolumn{9}{|c|}{ Biochemical inflammation marker } \\
\hline $\begin{array}{l}\text { Interleukin } 6 \text { (pg/ } \\
\mathrm{mL})^{\mathrm{b}}\end{array}$ & $87(23-357)$ & $32(11-145)$ & $150(55-693)$ & $<0.001$ & $44(9-211)$ & $80(28-320)$ & $181(55-814)$ & $<0.001$ \\
\hline $\mathrm{SpO}_{2}$ at admission $^{\mathrm{b}}$ & $95 \%(91-96)$ & $95 \%(92-96)$ & $94 \%(89-95)$ & 0.792 & $95 \%(92-97)$ & $95 \%(91-96)$ & $94 \%(92-96)$ & 0.638 \\
\hline $\begin{array}{l}\text { Oxygen therapy, no. } \\
(\%)\end{array}$ & & & & 0.249 & & & & $0.215^{*}$ \\
\hline $\begin{array}{l}\text { Mild, } \mathrm{O}_{2} \text { not neces- } \\
\text { sary }\end{array}$ & $37(17)$ & $23(22)$ & $14(12)$ & & $16(22)$ & $14(16)$ & $7(13)$ & \\
\hline $\begin{array}{l}\text { Moderate, } \mathrm{O}_{2} \text { neces- } \\
\text { sary }\end{array}$ & $124(58)$ & $57(56)$ & $67(60)$ & & $41(55)$ & $53(61)$ & $30(55)$ & \\
\hline $\begin{array}{l}\text { Severe, CPAP neces- } \\
\text { sary }\end{array}$ & $44(20)$ & $19(19)$ & $25(22)$ & & $11(15)$ & $19(22)$ & $14(26)$ & \\
\hline $\begin{array}{l}\text { Critical, needs intu- } \\
\text { bation in ICU }\end{array}$ & $10(5)$ & $3(3)$ & $7(6)$ & & $6(8)$ & $1(1)$ & $3(6)$ & \\
\hline ICU, no. (\%) & $12(6)$ & $5(5)$ & $7(6)$ & 0.439 & $6(8)$ & $2(2)$ & $4(7)$ & $0.207^{*}$ \\
\hline $\begin{array}{l}\text { Days of hospitaliza- } \\
\text { tion }^{\text {a }}\end{array}$ & $21.3 \pm 13.6$ & $20.3 \pm 11.1$ & $21.5 \pm 12.8$ & 0.468 & $20.1 \pm 13.5$ & $20.6 \pm 11$ & $22.2 \pm 11.2$ & 0.601 \\
\hline Death, no. $(\%)$ & $4(2)$ & $0(0)$ & $4(4)$ & $0.124 *$ & $1(1)$ & $1(1)$ & $2(4)$ & $0.540^{*}$ \\
\hline
\end{tabular}

No abdominal obesity (Waist circumference $<102 \mathrm{~cm}$ for males, $<88 \mathrm{~cm}$ for females); Abdominal obesity (waist circumference $\geq 102 \mathrm{~cm}$ for males, $\geq 88 \mathrm{~cm}$ for females); Normal weight (BMI from 18.5 to $<25 \mathrm{~kg} / \mathrm{m}^{2}$ ); Overweight (BMI from 25 to $<30 \mathrm{~kg} / \mathrm{m}^{2}$ ); Obesity $(\mathrm{BMI} \geq 30 \mathrm{~kg} /$ $\mathrm{m}^{2}$ ). Not available (NA); Body Mass Index (BMI); Waist-to-height ratio (WHtR); Chest x-ray (CXR); Interleukin 6 normal value $<10 \mathrm{pg} / \mathrm{mL}$; Oxygen saturation at admission $\left(\mathrm{SpO}_{2}\right)$

Categorial variables presented as number (percentage), and continuous variables as mean $( \pm \mathrm{SD})^{\mathrm{a}}$ or median (interquartile range) $)^{\mathrm{b}}$. To compare variables between different groups, the $\chi^{2}$ test or *Fisher's exact test was used for categorial variables

while there were no significant differences between patients with normal weight, with overweight or with BMI-based obesity ( $P=0.104 ; P=0.271$, respectively), (Table 1, Fig. 4b).

IL-6 values were significantly higher in patients with abdominal obesity than in those without $(P<0.001)$ as well as in patients with overweight and with BMI-based obesity compared to those with normal weight $(P<0.001)$ (Table 1, Fig. 4c, d).

There were no differences in age between patients with and without abdominal obesity or between BMI classes $(P=0.275 ; P=0.169)$ (Table 1). No significant gender differences were found between patients with or without abdominal obesity $(P=0.129)$, although there were more male patients with overweight or who suffered from BMI-based obesity than those with normal weight $(P=0.001)$ (Table 1).

There was no statistical difference in $\mathrm{SpO}_{2}$ at admission between patients with and without abdominal obesity or between patients with normal weight, with overweight and with BMI-based obesity $(P=0.792$ and $P=0.638$, respectively), although a trend toward lower $\mathrm{SpO} 2$ on admission was observed in patients with abdominal obesity compared to those without (Table 1).

There were no differences in the need for and level of invasiveness of oxygen therapy within the first few hours of hospital admission between patients with and without abdominal obesity $(P=0.249)$ or with normal weight, with overweight or those with BMI-based obesity $(P=0.215)$ (Table 1). 


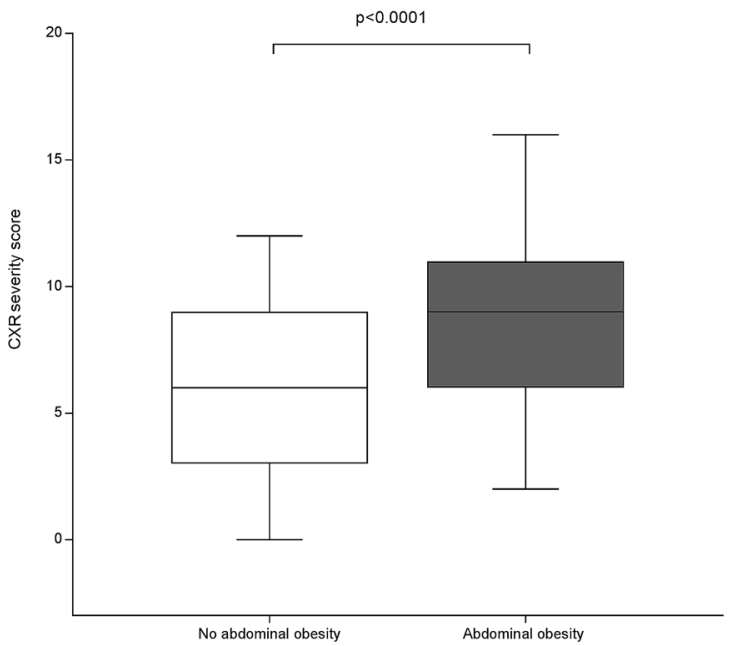

回
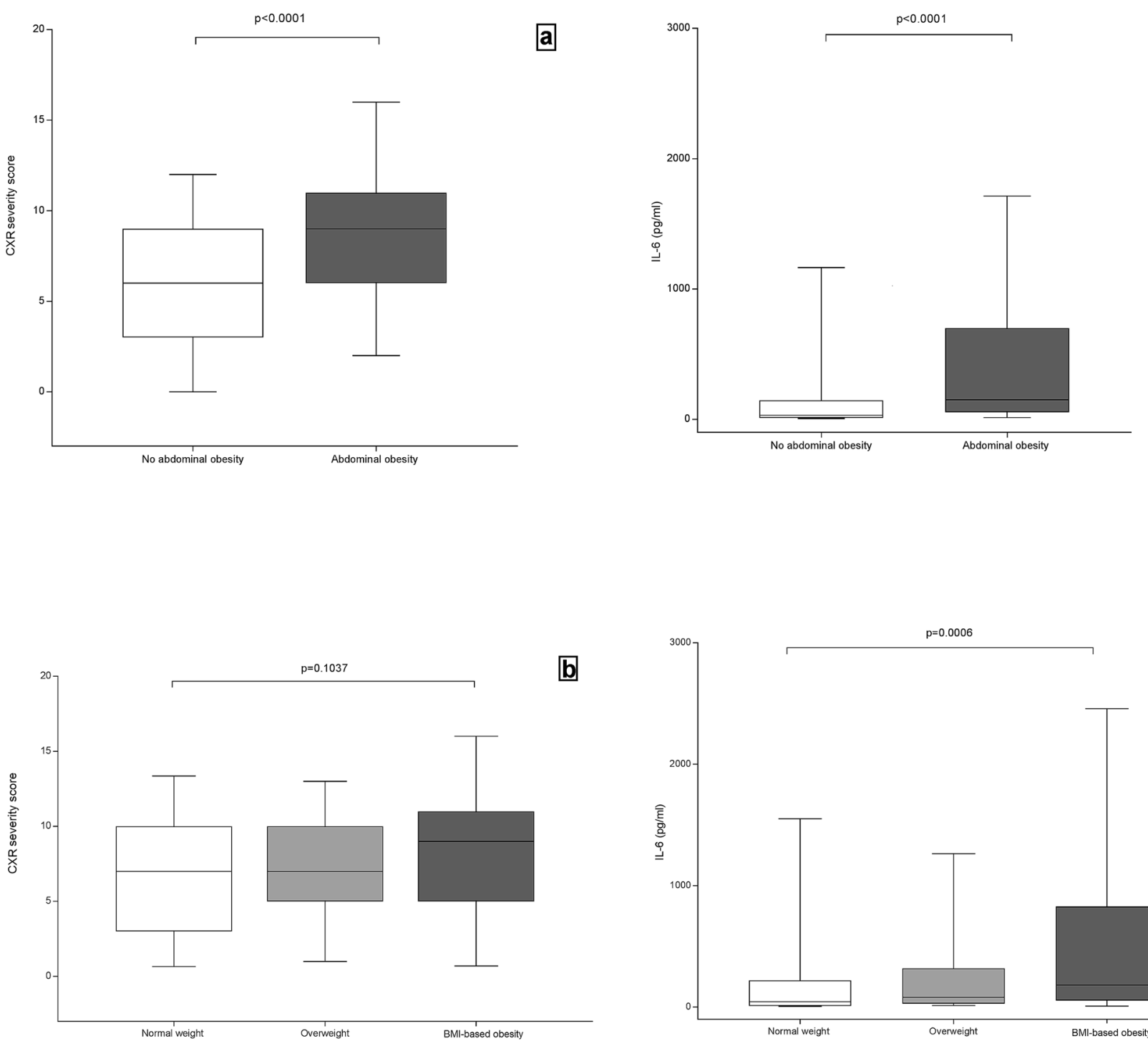

Fig. 4 Chest X-ray severity scores of patients with and without abdominal obesity (a) and BMI classes (b), and IL-6 values of patients with and without abdominal obesity (c) and BMI classes (d). Chest X-ray (CXR); Interleukin 6 (IL-6); Body Mass Index (BMI). No abdominal obesity (Waist circumference $<102 \mathrm{~cm}$ for

Also, in terms of the length of the hospital stays (in days), there was no difference between patients with and without abdominal obesity or between patients with normal weight, with overweight or who suffered from BMI-based obesity ( $P=0.468$ and $P=0.601$, respectively) (Table 1 ).

In our sample 4 patients died from COVID-19 complications. All of them had abdominal obesity and 2 of them were also affected by BMI-based obesity (Table 1).

In our cohort, hypertension, diabetes, cardiovascular disease, chronic kidney failure and bronchial asthma were the most common comorbidities. Diabetes was more frequent in patients with abdominal obesity than in those without, but the difference was not significant $(P=0.067)$ (Table 1$)$.
C.

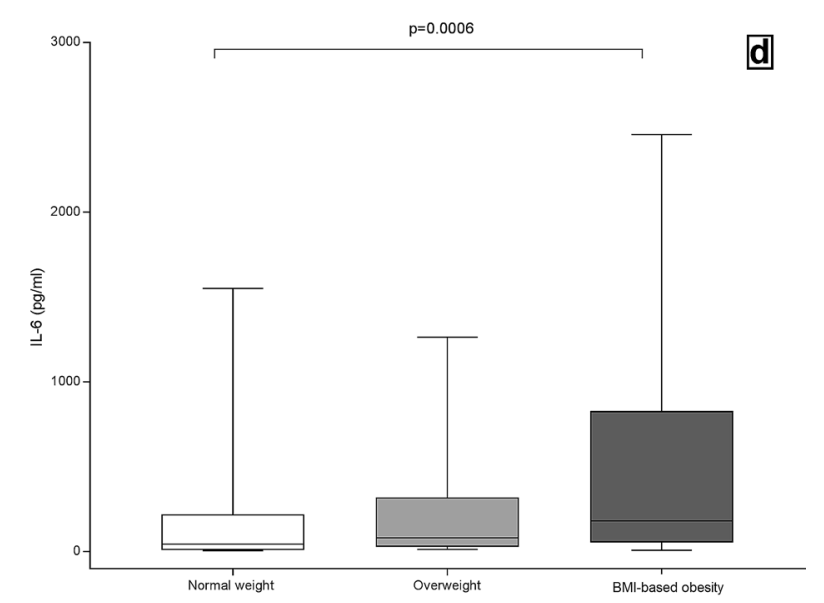

males, $<88 \mathrm{~cm}$ for females); Abdominal obesity (waist circumference $\geq 102 \mathrm{~cm}$ for males, $\geq 88 \mathrm{~cm}$ for females); Normal weight (BMI from 18.5 to $<25 \mathrm{~kg} / \mathrm{m}^{2}$ ); Overweight (BMI from 25 to $<30 \mathrm{~kg} / \mathrm{m}^{2}$ ); BMI-based obesity (BMI $\geq 30 \mathrm{~kg} / \mathrm{m}^{2}$ ); The figure was created by an author (V.M.) using the program GraphPad—Prism 7

Hypertension was significantly more common in patients with overweight or with BMI-based obesity than in those with normal weight $(P=0.001)$ (Table 1$)$.

\section{Adiposity indexes and clinical features}

Waist circumference and WHtR showed a higher correlation with CXR severity scores than BMI $(r=0.43$ [0.30-0.55], $P<0.001 ; r=0.41$ [0.28-0.53], $P<0.001 ; r=0.17$ [0.04-0.29], $P=0.012$, respectively).

IL-6 correlated more closely with both waist circumference and WHtR than BMI $(r=0.46$ [0.33-0.58], $P<0.001$; 
$r=0.45$ [0.32-0.57], $P<0.001 ; r=0.34$ [0.21-0.46], $P<0.001$, respectively).

$\mathrm{SpO}_{2}$ at admission correlated negatively with both waist circumference and WHtR $(r=-0.17$ [ -0.29 to -0.04$]$, $P=0.025 ; \mathrm{r}=-0.18$ [ -0.30 to -0.05$], P=0.017$, respectively), while no significant correlation was found with BMI $(r=-0.07$ [ -0.19 to 0.06$], P=0.389)$.

$\mathrm{SpO}_{2}$ at admission and IL-6 significantly correlated with CXR severity scores $(r=-0.45[-0.57$ to -0.32$]$, $P<0.001 ; r=0.48$ [0.35-0.59], $P<0.001$, respectively).

\section{ROC analysis}

ROC curves were used to assess the identifying ability of waist circumference, WHtR and BMI in relation to a high CXR severity score $(\geq 8)$. The best cut-off for a high score $(\geq 8)$ for waist circumference was $102 \mathrm{~cm}$ in men and $86 \mathrm{~cm}$ in women, 0.58 for WHtR and 27.7 for BMI. The AUCs for waist circumference and WHtR were significantly higher than those for BMI to identify a high CXR severity score $(\geq 8)(0.68$ [0.60-0.75] and 0.67 [0.60-0.74] vs 0.58 [0.51-0.66], $P=0.001$ ) (Fig. 5).

\section{CXR severity scores and IL- 6 among patients with different adiposity indexes}

We examined CXR severity scores and IL-6 in the three categories of BMI in relation to the concomitant presence of abdominal obesity phenotype (Table 2 ). CXR severity scores were higher in patients with abdominal obesity than in patients without abdominal obesity among the subgroup of patients with overweight $(P<0.001)$ and those with BMIbased obesity $(P=0.043)$. Even in the subgroup of patients with normal weight, there was a trend towards higher CXR severity scores in those with abdominal obesity, although these were not statistically significant $(P=0.094)$.

IL-6 values were higher in patients with abdominal obesity phenotype than in patients without abdominal
Fig. 5 AUCs of waist circumference, waist-to-height-ratio and body mass index for establishing a high chest X-ray severity score. Waist-to-heightratio (WHtR) and Body Mass Index (BMI); Receiver Operating Characteristics (ROC). The figure was created by an author (V.M.) using the program SAS 9.4 (SAS Institute Inc., Cary, NC, USA)

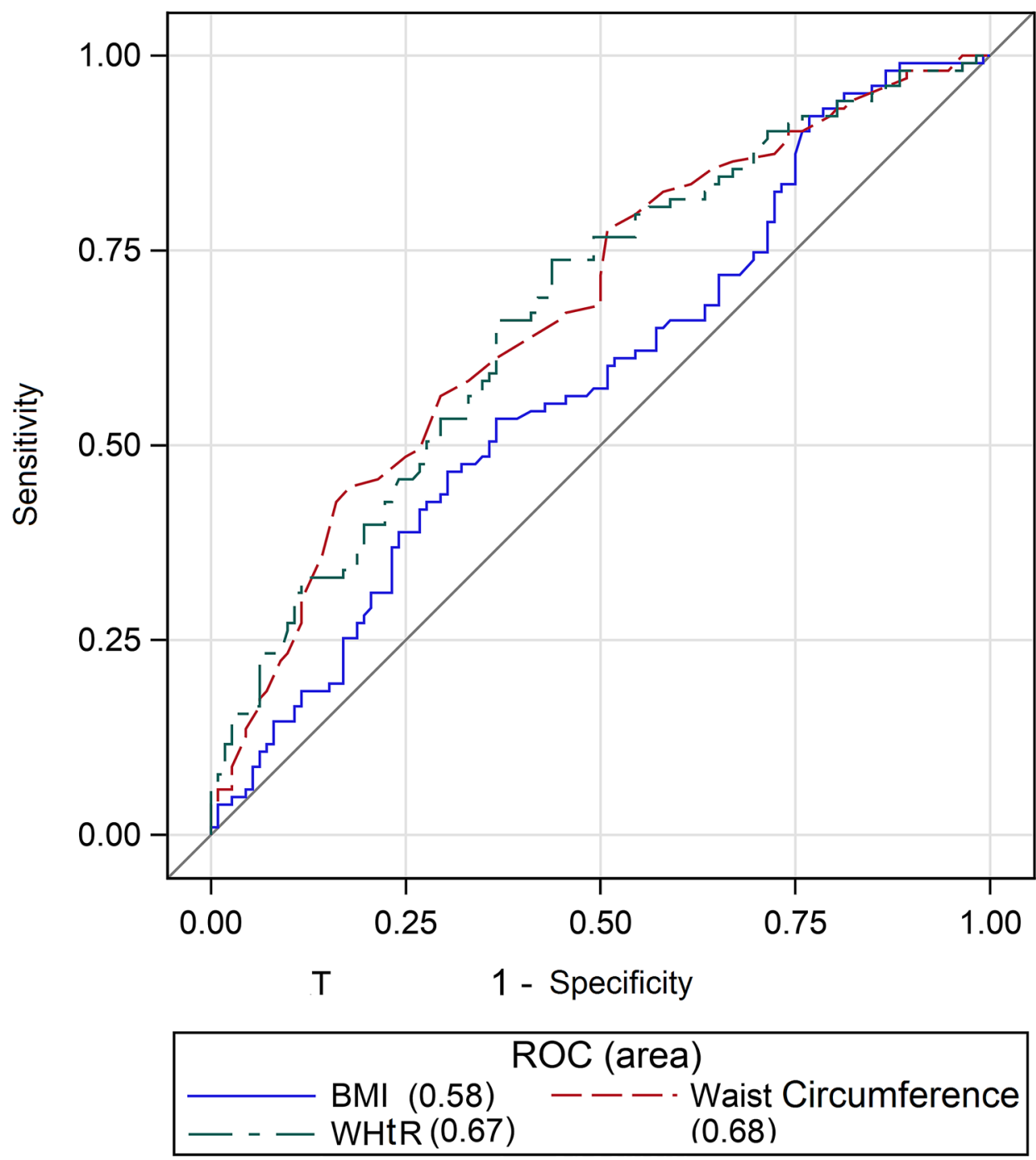


Table 2 Chest x-ray severity score and IL-6 values among patients with different adiposity indexes

\begin{tabular}{lllr}
\hline & \multicolumn{2}{l}{ Abdominal obesity } & \multirow{2}{*}{$p$-value } \\
\cline { 2 - 3 } & No & Yes & \\
& $n=102(47 \%)$ & $n=113(53 \%)$ & \\
\hline Normal weight $\mathbf{n = 7 4 ( 3 4 \% )}$ & $n=57(77 \%)$ & $n=17(23 \%)$ & 0.094 \\
CXR severity score & $6.0(3.0-9.0)$ & $9.0(6.0-11.0)$ & $<\mathbf{0 . 0 0 1}$ \\
IL-6 values & $21.0(8.0-100.0)$ & $140.0(70.0-724.0)$ & \\
Overweight, $\mathbf{n}=\mathbf{8 7}(\mathbf{4 1 \%})$ & $n=38(44 \%)$ & $n=49(56 \%)$ & $\mathbf{0 . 0 4 3}$ \\
CXR severity score & $7.0(3.0-8.0)$ & $8.0(5.0-10.0)$ & $\mathbf{0 . 0 4 6}$ \\
IL-6 values & $41.0(19.0-178.0)$ & $96.0(45.0-328.0)$ & \\
BMI-based obesity, $\mathbf{n = 5 4}(\mathbf{2 5 \%})$ & $n=7(13 \%)$ & $n=47(87 \%)$ & $\mathbf{0 . 0 0 1}$ \\
CXR severity score & $2.0(0.0-4.0)$ & $10.0(7.0-12.0)$ & $\mathbf{0 . 0 4 7}$ \\
IL-6 values & $52.0(27.0-169.0)$ & $222.0(80.0-889.0)$ & \\
\hline
\end{tabular}

No abdominal obesity (Waist circumference $<102 \mathrm{~cm}$ for males, $<88 \mathrm{~cm}$ for females); Abdominal obesity (waist circumference $\geq 102 \mathrm{~cm}$ for males, $\geq 88 \mathrm{~cm}$ for females); Normal weight (BMI from 18.5 to $<25 \mathrm{~kg}$ / $\mathrm{m}^{2}$ ); Overweight (BMI from 25 to $\left.<30 \mathrm{~kg} / \mathrm{m}^{2}\right)$; BMI-based obesity (BMI $\left.\geq 30 \mathrm{~kg} / \mathrm{m}^{2}\right)$. Chest $\mathrm{X}-$ ray $(\mathrm{CXR})$; Interleukin 6 (IL-6) normal value $<10 \mathrm{pg} / \mathrm{mL}$

Continuous variables as median (interquartile range) obesity among the subgroup of patients with normal weight $(P<0.001)$, with overweight $(P=0.046)$ and those with BMI-based obesity $(P=0.047)$.

\section{Risk factors associated with a CXR severity score $\geq 8$}

Poisson regression with a robust error variance analysis was carried out to identify the risk factors associated with a high CXR severity score $(\geq 8)$ in hospitalized COVID-19 patients (Table 3). A univariate analysis showed that abdominal
Table 3 Univariate and multivariate logistic regression for the evaluation of risk factors associated with high chest $\mathrm{x}$-ray severity score $(\geq 8)$

\begin{tabular}{|c|c|c|c|c|}
\hline & \multicolumn{2}{|l|}{ Univariate } & \multicolumn{2}{|l|}{ Multivariate } \\
\hline & RR (CI 95\%) & $p$-value & RR (CI 95\%) & $p$-value \\
\hline Age & $1.01(0.99-1.02)$ & 0.234 & $1.00(0.99-1.01)$ & 0.849 \\
\hline \multicolumn{5}{|l|}{ Race } \\
\hline Caucasian vs Non-Caucasian & $0.79(0.55-1.16)$ & 0.235 & - & \\
\hline \multicolumn{5}{|l|}{ Gender } \\
\hline Male vs Female & $1.35(0.97-1.90)$ & 0.072 & $1.35(0.97-1.87)$ & 0.078 \\
\hline Smoke & $0.95(0.62-1.46)$ & 0.805 & - & \\
\hline \multicolumn{5}{|l|}{ Comorbidities } \\
\hline Abdominal obesity & $1.68(1.24-2.28)$ & $<0.001$ & $1.75(1.25-2.45)$ & 0.001 \\
\hline BMI-based Obesity & $1.28(0.96-1.71)$ & 0.088 & $1.02(0.74-1.39)$ & 0.915 \\
\hline Hypertension & $1.35(0.99-1.83)$ & 0.055 & $1.17(0.84-1.65)$ & 0.355 \\
\hline Diabetes Mellitus & $1.24(0.88-1.75)$ & 0.227 & - & \\
\hline Ischemic cardiopathy & $1.03(0.61-1.72)$ & 0.924 & - & \\
\hline Chronic heart failure & $1.23(0.59-2.57)$ & 0.571 & - & \\
\hline Atrial fibrillation & $0.94(0.51-1.73)$ & 0.843 & - & \\
\hline Chronic Obstructive Pulmonary Disease & $0.81(0.38-1.77)$ & 0.604 & - & \\
\hline Bronchial asthma & $1.65(1.04-2.62)$ & $\mathbf{0 . 0 3 5}$ & $1.73(1.07-2.81)$ & 0.026 \\
\hline Chronic Kidney Failure & $0.76(0.31-1.88)$ & 0.551 & - & \\
\hline IL-6 (pg/ml) & $1.03(1.01-1.05)$ & 0.002 & $1.00(0.99-1.03)$ & 0.313 \\
\hline $\mathrm{SpO}_{2}$ at admission & $0.96(0.94-0.97)$ & $<0.001$ & $0.96(0.94-0.97)$ & $<0.001$ \\
\hline
\end{tabular}

Abdominal obesity (waist circumference $\geq 102 \mathrm{~cm}$ for males, $\geq 88 \mathrm{~cm}$ for females); Normal weight (BMI from 18.5 to $<25 \mathrm{~kg} / \mathrm{m}^{2}$ ); Overweight (BMI from 25 to $<30 \mathrm{~kg} / \mathrm{m}^{2}$ ); BMI-based obesity (BMI $\geq 30 \mathrm{~kg} / \mathrm{m}^{2}$ ); Interleukin 6 (IL-6); Oxygen saturation at admission $\left(\mathrm{SpO}_{2}\right)$; Risk ratio (RR); Confidence Interval (CI) 
obesity (RR: 1.68, 95\% CI: 1.24-2.28, $P<0.001$ ), bronchial asthma (RR: $1.65,95 \% \mathrm{CI}: 1.04-2.62, P=0.035)$, BMIbased obesity (RR: $1.28,95 \% \mathrm{CI}: 0.96-1.71, P=0.088$ ), IL-6 values (RR: $1.03,95 \% \mathrm{CI}: 1.01-1.05, P=0.002)$ and $\mathrm{SpO}_{2}$ at admission (RR: $0.96,95 \%$ CI $0.94-0.97, P<0.001$ ) were significantly associated with a CXR severity score $\geq 8$. On a multivariate analysis, considering variables associated in univariate models with $p<0.1$ and forcing age, abdominal obesity (RR: $1.75,95 \% \mathrm{CI}: 1.25-2.45, P=0.001$ ), bronchial asthma (RR: $1.73,95 \% \mathrm{CI}: 1.07-2.81, P=0.026)$ and $\mathrm{SpO}_{2}$ at admission (RR: 0.96, 95\% CI: 0.94-0.97, $P<0.001$ ) were still independently associated with high CXR severity scores $(\geq 8)$.

\section{Discussion}

In this study, we analyzed the impact of different adiposity indexes on CXR severity scores in a hospitalized cohort affected by COVID-19. We observed that abdominal obesity phenotype was more closely associated with the risk of serious COVID-19-related lung abnormalities than was BMI-based obesity.

Patients with abdominal obesity showed significantly higher CXR severity scores and had higher rates of CXR severity scores $\geq 8$ compared to those without abdominal obesity, while patients with normal weight, with overweight and those with BMI-based obesity had no significant differences in CXR severity scores or in the rates of CXR severity scores $\geq 8$. The score of 8 for CXR has been recently associated with in-hospital mortality of patients with COVID-19 [22].

The correlation of CXR severity scores with waist circumference and WHtR was higher than correlation with BMI classes. Therefore, there was also a significant difference in the AUCs of waist circumference and WHtR compared to BMI when detecting high CXR severity scores. Moreover, among the subgroup of patients with overweight and those with BMI-based obesity, those with a concomitant presence of abdominal obesity phenotype had significantly higher CXR severity scores. Also, in the subgroup of patients with normal weight, there was a trend toward higher CXR severity scores in those with a concomitant presence of abdominal obesity phenotype, although this did not reach statistical significance probably due to the small sample size of this subgroup.

Recently, Stefan et al. [40] stressed that anthropometric indexes, such as waist and hip circumferences, are important to better estimate the risk of complications in patients with COVID-19, in addition to the standard hospital parameters including BMI. Although BMI is widely used to define BMI-based obesity, further characterizing patients by assessing fat distribution and abdominal obesity might be a more accurate way to stratify patients $[16,34,40,41]$. Therefore, waist circumference is widely used in clinical practice as a required criterion for the diagnosis of metabolic syndrome, which has recently been associated with a higher risk of serious illness with COVID-19 [41, 42].

Recent data found that patients with central obesity assessed by waist circumference threshold and WHR, had a higher risk of severe COVID-19 [34]. Another study has suggested that visceral adipose tissue and CT-derived upper abdominal waist circumference increase the likelihood of severe COVID-19 in overweight patients who do not meet the diagnostic criteria for BMI-based obesity [32].

Patients with obesity are predisposed to respiratory dysfunction, and have an increased risk of severe asthma and hypoventilation-associated pneumonia [8, 9, 43]. Toussie et al. [17] have already demonstrated that both CXR severity scores and BMI-based obesity were independent predictors for hospitalization and intubation in COVID-19 patients. However, in their study, anthropometric parameters of fat distribution (e.g. waist circumference) were not available, so that any prediction and comparison of potential outcomes was not possible [17]. In our study, we found that $\mathrm{SpO}_{2}$ at admission correlated negatively with waist circumference and WHtR, while no significant correlation was found with BMI. In addition, when performing a multivariate analysis, our results indicated that abdominal obesity and $\mathrm{SpO}_{2}$ at admission were independently associated with a high CXR severity score. A previous study reported that obesity was a strong independent contributor to low $\mathrm{SpO}_{2}$, with a negative correlation between $\mathrm{BMI}$ and $\mathrm{SpO}_{2}$; nevertheless, the authors had not investigated a possible correlation with indicators of abdominal fat distribution [9].

In this study, we did not observe significant differences in the need for and invasiveness of oxygen therapy between patients with and without abdominal obesity or with normal weight, with overweight or those with BMI-based obesity. The inconsistent results may be due to the small size of each subgroup.

A recent study reported that visceral fat deposition within the abdomen seems to have a stronger association with the need for ICU admission and intubation for COVID-19 than other parameters, such as severity of interstitial pneumonia, markers of inflammation, age, gender or comorbidities [33]. This supports the suggestion that upper trunk fat can contribute to respiratory drive and gas exchange impairment [44]. Excessive fat in the chest walls and abdomen has a high mechanical impact on lung functionalities [8]. Abdominal obesity and excess visceral fat adversely affect the chest walls and lung compliance due to their accumulation, increasing intra-abdominal pressure and mechanical compression of the diaphragm, lungs, and chest cavity [8].

Interestingly, ectopic fat depots have been highlighted as new markers of major COVID-19 complications [29, 
$33,45,46]$. A recent study reported that in patients with SARS-CoV-2 visceral adiposity and high intramuscular fat deposition were independent risk factors for critical illness [31]. However, they did not find differences in BMI [31]. In addition, Deng et al. [29] not only confirmed that obesity is a major and independent risk factor for COVID-19 complications in young adults [47], but also pointed to ectopic and visceral fat depots as new markers of that risk. The authors found that CT imaging showed significantly higher fatty liver and epicardial adipose tissue (EAT) in severely and critically ill patients with COVID-19 under 40 years old compared with those with a milder form of the disease [47]. The higher risk for people with obesity of developing severe COVID-19 cardiac and pulmonary injuries can be attributed to multiple factors, such as a chronic inflammatory status, a delayed immune response and possibly fat tissue serving as a reservoir for the virus [48]. However, ectopic and visceral fat accumulation is an additional mechanism which may not be immediately identifiable. We now face a different phenotype of the high-risk patient who is much younger and who certainly suffers from obesity but with prominent visceral obesity [30]. The findings of Deng et al. [29] may provide new insights to untangle the intricate, and still unclear, physiopathologic pathways leading to COVID-19 organ damage. EAT has been recognized as highly inflammatory and dense with macrophage infiltrates [49] which can cause upregulation and increase the release of pro-inflammatory cytokines, such as IL-6 [50]. The role of EAT in causing and worsening COVID-19 cardiac complications has recently emerged [51]. It has been recently reported that EAT inflammation was linked to more severe COVID-19 in hospitalized patients with abdominal obesity phenotype [46] and it is associated with the quantitative burden of COVID-19 pneumonia [52].

In our study, we showed that IL-6 values correlated more closely with both waist circumference and WHtR than with BMI. We also found a significant correlation of IL-6 concentrations with CXR severity scores. It is worth noting that IL-6 values were higher in patients with abdominal obesity phenotype than in patients without abdominal obesity among the subgroup of patients with normal weight, with overweight and those with BMI-based obesity.

Abdominal obesity is responsible for a pro-inflammatory state due to abnormal adipokine and cytokine secretion [25, 48]. The distribution of adipose tissue has a major influence on the immune system [53]. The elevated inflammatory cytokine levels observed in patients with high visceral fat may be associated with increased obesity-associated morbidity in infections [25, 48]. Recent studies have shown that IL-6 is an independent risk factor for developing severe COVID-19 [49, 54] and visceral adipose tissue is one of the primary sources of IL-6 secretion [55]. The creation of an auto-regenerating inflammation loop in this pro-inflammatory condition by the recruitment of immune cells impairs the immune system [56]. In this condition, a viral infection could simply start a weakened immune response, leading to a cytokine storm with an overproduction of pro-inflammatory cytokines. The cytokine storm could lead to the vascular hyper-permeability and multi-organ failure seen in severe cases of COVID-19 [57, 58]. Interestingly, another factor, which could contribute to an increase in IL-6 secretion, is growth hormone deficiency [59], which is characterized by an abnormal fat distribution and increased visceral fat accumulation [60]. It has recently been hypothesized that growth hormone $(\mathrm{GH})$ insufficiency may be the missing link between obesity, male gender, age, and COVID-19 severity and that patients with COVID-19 might benefit from recombinant $\mathrm{GH}$ treatment [61].

\section{Strengths and limits}

As far as we know, this is the first study, which has investigated the relationship between abdominal obesity phenotype and CXR severity scores in hospitalized COVID-19 patients. There are several limitations to our study. First, it was a retrospective, single-center study with a small sample group. Most patients were of Caucasian ethnicity so the applicability of the waist circumference threshold to other ethnic groups requires further investigation. Second, waist circumference assessment is subject to operator variability and this could have led to some bias. Moreover, due to the need to take patients' anthropometrics measurements while standing, they were not measured in those who arrived at the hospital in a critical condition and who have therefore not been included in our study. This might represent a limit of the study since it probably excluded some of the more seriously ill patients. Third, we extracted the information on comorbidities from the patients' records, assuming there was no comorbidity if none was mentioned. Finally, we did not use CT or MRI as a direct method for the detection of abdominal visceral fat. However, in daily clinical practice, it is not always possible to use these techniques and therefore indirect measures, such as waist circumference, are possibly useful in the initial examination of hospitalized COVID19 patients. Nevertheless, our study offered new insights into the detailed classification of hospitalized patients with COVID-19, adopting threshold values of waist circumference as indicators for abdominal obesity, which might be associated to the severity of lung abnormalities better than BMI.

\section{What is already known on this subject?}

The literature supports the claim that CXR severity scores and BMI-based obesity are independent predictors of hospitalization of COVID-19 patients. It has been shown that 
abdominal visceral obesity increases the risk of complications in COVID-19 patients; however, the evidence is limited and the extent of these associations is not fully understood.

\section{What your study adds?}

The study shows that abdominal obesity phenotype rather than BMI-based obesity is an independent risk factor for a high CXR severity score in hospitalized COVID-19 patients. Moreover, abdominal fat distribution defined by waist circumference might be better than BMI in indicating a high CXR severity score. In clinical hospital practice, the waist circumference should be assessed and patients with abdominal obesity phenotype should be monitored closely.

\section{Conclusion}

This study showed that abdominal obesity is better associated with a high CXR severity score than BMI-based obesity in hospitalized COVID-19 patients. Therefore, when visiting the patient in a hospital setting, subjects with abdominal obesity should be monitored closely.

Funding The study, conducted at the IRCCS Policlinico San Donato, was partially financed by the Italian Ministry of Health.

Code availability Not applicable.

Availability of data and material The datasets generated and/or analyzed during this study will be made available upon reasonable request to the corresponding author.

\section{Declarations}

Ethics approval This research study was conducted retrospectively from data obtained for clinical purposes and it was approved by our Ethics Committee (Ethics Committee of San Raffaele Clinical Research Hospital; protocol code 37/int/2020). Patient confidentiality was protected by assigning anonymous identification codes.

Consent to participate Due to the retrospective nature of this analysis, informed consent was not necessary and thus was waived.

Conflict of interest The authors declare that they have no conflicts of interest.

\section{References}

1. World Health Organization. Coronavirus disease 2019. n.d. https:// www.who.int/emergencies/diseases/novel-coronavirus-2019.

2. Berlin DA, Gulick RM, Martinez FJ (2020) Severe Covid-19. N Engl J Med. https://doi.org/10.1056/NEJMcp2009575

3. Kopelman PG (2000) Obesity as a medical problem. Nature 404:635-643. https://doi.org/10.1038/35007508
4. Allison DB, Downey M, Atkinson RL, Billington CJ, Bray GA, Eckel RH et al (2008) Obesity as a disease: a white paper on evidence and arguments commissioned by the Council of the Obesity Society. Obesity 16:1161-1177. https://doi.org/10.1038/oby.2008. 231

5. World Health Organization. Health topics. Obesity. https://www. who.int/topics/obesity/en

6. Fezeu L, Julia C, Henegar A, Bitu J, Hu FB, Grobbee DE et al (2011) Obesity is associated with higher risk of intensive care unit admission and death in influenza A (H1N1) patients: a systematic review and meta-analysis. Obes Rev an Off J Int Assoc Study Obes 12:653-659. https://doi.org/10.1111/j.1467-789X.2011. 00864.x

7. Maccioni L, Weber S, Elgizouli M, Stoehlker A-S, Geist I, Peter $\mathrm{H}-\mathrm{H}$ et al (2018) Obesity and risk of respiratory tract infections: results of an infection-diary based cohort study. BMC Public Health 18:271. https://doi.org/10.1186/s12889-018-5172-8

8. Dixon AE, Peters U (2018) The effect of obesity on lung function. Expert Rev Respir Med 12:755-767. https://doi.org/10.1080/ 17476348.2018.1506331

9. Kapur VK, Wilsdon AG, Au D, Avdalovic M, Enright P, Fan VS et al (2013) Obesity is associated with a lower resting oxygen saturation in the ambulatory elderly: results from the cardiovascular health study. Respir Care 58:831-837. https://doi.org/10. 4187/respcare.02008

10. Todisco P, Donini LM (2020) Eating disorders and obesity (ED\&O) in the COVID-19 storm. Eat Weight Disord 1-4. doi:https://doi.org/10.1007/s40519-020-00938-z.

11. Malavazos AE, Corsi Romanelli MM, Bandera F, Iacobellis $\mathrm{G}$ (2020) Targeting the adipose tissue in COVID-19. Obesity 28:1178-1179. https://doi.org/10.1002/oby.22844

12. Petrilli CM, Jones SA, Yang J, Rajagopalan H, O'Donnell L, Chernyak Y et al (2020) Factors associated with hospital admission and critical illness among 5279 people with coronavirus disease 2019 in New York City: prospective cohort study. BMJ 369:m1966. https://doi.org/10.1136/bmj.m1966

13. Busetto L, Bettini S, Fabris R, Serra R, Dal Pra C, Maffei P, Rossato M, Fioretto P, Vettor R (2020) Obesity and COVID-19: an Italian Snapshot. Obesity 28:1600-1605. https://doi.org/10.1002/ oby. 22918

14. Kim T, Roslin M, Wang JJ, Kane J, Hirsch JS, Ji KE (2020) Body mass index as a risk factor for clinical outcomes in patients hospitalized with COVID-19 in New York. Obesity. https://doi.org/ 10.1002/oby. 23076

15. Simonnet A, Chetboun M, Poissy J, Raverdy V, Noulette J, Duhamel A et al (2020) High prevalence of obesity in severe acute respiratory syndrome Coronavirus-2 (SARS-CoV-2) Requiring Invasive Mechanical Ventilation. Obesity 28:1195-1199. https:// doi.org/10.1002/oby.22831

16. ACR Recommendations for the use of Chest Radiography and Computed Tomography (CT) for Suspected COVID-19 Infection n.d. https://www.acr.org/Advocacy-and-Economics/ACR-Posit ion-Statements/Recommendations-for-Chest-Radiography-andCT-for-Suspected-COVID19-Infection. Accessed 2 sJuly 2020

17. Toussie D, Voutsinas N, Finkelstein M, Cedillo MA, Manna S, Maron SZ et al (2020) Clinical and chest radiography features determine patient outcomes in young and middle-aged adults with COVID-19. Radiology 297:E197-206. https://doi.org/10.1148/ radiol.2020201754

18. Schiaffino S, Tritella S, Cozzi A, Carriero S, Blandi L, Ferraris L et al (2020) Diagnostic performance of chest X-ray for COVID-19 pneumonia during the SARS-CoV-2 pandemic in Lombardy, Italy. J Thorac Imaging 35:W105-W106. https://doi.org/10.1097/RTI. 0000000000000533

19. Kim H, Hong H, Yoon SH (2020) Diagnostic performance of CT and reverse transcriptase-polymerase chain 
reaction for coronavirus disease 2019: a meta-analysis. Radiology 2020:201343. https://doi.org/10.1148/radiol.2020201343

20. Taylor E, Haven K, Reed P, Bissielo A, Harvey D, McArthur C, Bringans C, Freundlich S, Ingram RJ, Perry D, Wilson F, Milne D, Modahl L, Huang QS, Gross D, Widdowson MA, Grant CC, SHIVERS Investigation Team (2015) A chest radiograph scoring system in patients with severe acute respiratory infection: a validation study. BMC Med Imaging. 15:61. https://doi.org/10.1186/ s12880-015-0103-y

21. Borghesi A, Maroldi R (2020) COVID-19 outbreak in Italy: experimental chest $\mathrm{X}$-ray scoring system for quantifying and monitoring disease progression. Radiol Med. 125(5):509-513. https://doi.org/ 10.1007/s11547-020-01200-3

22. Borghesi A, Zigliani A, Golemi S, Carapella N, Maculotti P, Farina D, Maroldi R (2020) Chest X-ray severity index as a predictor of in-hospital mortality in coronavirus disease 2019: a study of 302 patients from Italy. Int J Infect Dis. 96:291-293. https:// doi.org/10.1016/j.ijid.2020.05.021

23. Cai Q, Chen F, Wang T, Luo F, Liu X, Wu Q et al (2020) Obesity and COVID-19 severity in a Designated Hospital in Shenzhen, China. Diabetes Care 43:1392-1398. https://doi.org/10.2337/ dc20-0576

24. Okorodudu DO, Jumean MF, Montori VM, Romero-Corral A, Somers VK, Erwin PJ et al (2010) Diagnostic performance of body mass index to identify obesity as defined by body adiposity: a systematic review and meta-analysis. Int J Obes 34:791-799. https://doi.org/10.1038/ijo.2010.5

25. Honce R, Schultz-Cherry S (2019) Impact of obesity on influenza A Virus pathogenesis, immune response, and evolution. Front Immunol 10:1071. https://doi.org/10.3389/fimmu.2019.01071

26. Dhurandhar NV, Bailey D, Thomas D (2015) Interaction of obesity and infections. Obes Rev an Off J Int Assoc Study Obes 16:1017-1029. https://doi.org/10.1111/obr.12320

27. Kanneganti T-D, Dixit VD (2012) Immunological complications of obesity. Nat Immunol 13:707-712. https://doi.org/10.1038/ni. 2343

28. Neeland IJ, Ross R, Després J-P, Matsuzawa Y, Yamashita S, Shai I et al (2019) Visceral and ectopic fat, atherosclerosis, and cardiometabolic disease: a position statement. Lancet Diabetes Endocrinol 7:715-725. https://doi.org/10.1016/S2213-8587(19) 30084-1

29. Deng M, Qi Y, Deng L, Wang H, Xu Y, Li Z et al (2020) Obesity as a potential predictor of disease severity in young COVID-19 patients: a retrospective study. Obesity. https://doi.org/10.1002/ oby. 22943

30. Iacobellis G, Malavazos AE, Ferreira T (2020) COVID-19 rise in Younger adults with Obesity: Visceral Adiposity can predict the Risk. Obesity (Silver Spring). https://doi.org/10.1002/oby.22951

31. Yang Y, Ding L, Zou X, Shen Y, Hu D, Hu X et al (2020) Visceral adiposity and high intramuscular fat deposition independently predict critical illness in patients with Sars-COV-2. Obesity. https:// doi.org/10.1002/oby.22971

32. Petersen A, Bressem K, Albrecht J, Thieß H-M, Vahldiek J, Hamm B et al (2020) The role of visceral adiposity in the severity of COVID-19: highlights from a unicenter cross-sectional pilot study in Germany. Metabolism. https://doi.org/10.1016/j.metabol.2020. 154317

33. Watanabe M, Caruso D, Tuccinardi D, Risi R, Zerunian M, Polici M, Pucciarelli F, Tarallo M, Strigari L, Manfrini S, Mariani S, Basciani S, Lubrano C, Laghi A, Gnessi L (2020) Visceral fat shows the strongest association with the need of intensive care in patients with COVID-19. Metabolism 111:154319. https://doi. org/10.1016/j.metabol.2020.154319

34. Zhu Z, Hasegawa K, Ma B, Fujiogi M, Camargo CAJ, Liang L (2020) Association of obesity and its genetic predisposition with the risk of severe COVID-19: Analysis of population-based cohort data. Metabolism 112:154345. https://doi.org/10.1016/j.metabol. 2020.154345

35. Grundy SM, Cleeman JI, Daniels SR, Donato KA, Eckel RH, Franklin BA et al (2005) Diagnosis and management of the metabolic syndrome: an American Heart Association/National Heart, Lung, and Blood Institute scientific statement: Executive Summary. Crit Pathw Cardiol 4:198-203. https://doi.org/10.1097/ 00132577-200512000-00018

36. Centers for Disease Control and Prevention. Defining Adult Overweight and Obesity n.d. https://www.cdc.gov/obesity/adult/defin ing.html.

37. Monaco CG, Zaottini F, Schiaffino S, Villa A, Della Pepa G, Carbonaro LA, Menicagli L, Cozzi A, Carriero S, Arpaia F, Di Leo G, Astengo D, Rosenberg I, Sardanelli F (2020) Chest X-ray severity score in COVID-19 patients on emergency department admission: a two-centre study. Eur Radiol Exp 4(1):68. https://doi.org/10. 1186/s41747-020-00195-w

38. DeLong ER, DeLong DM, Clarke-Pearson DL (1988) Comparing the areas under two or more correlated receiver operating characteristic curves: a nonparametric approach. Biometrics 44:837-845

39. Zou G (2004) A modified poisson regression approach to prospective studies with binary data. Am J Epidemiol 159:702-706. https://doi.org/10.1093/aje/kwh090

40. Stefan N, Birkenfeld AL, Schulze MB, Ludwig DS (2020) Obesity and impaired metabolic health in patients with COVID19. Nat Rev Endocrinol 16:341-342. https://doi.org/10.1038/ s41574-020-0364-6

41. Bansal R, Gubbi S, Muniyappa R (2020) Metabolic Syndrome and COVID 19: Endocrine-Immune-Vascular Interactions Shapes Clinical Course. Endocrinology. https://doi.org/10.1210/endocr/ bqaa112

42. Suliga E, Ciesla E, Głuszek-Osuch M, Rogula T, Głuszek S, Kozieł D (2019) The usefulness of anthropometric indices to identify the risk of metabolic syndrome. Nutrients 11:2598. https:// doi.org/10.3390/nu11112598

43. Tashiro H, Shore SA (2019) Obesity and severe asthma. Allergol Int. 68(2):135-142. https://doi.org/10.1016/j.alit.2018.10.004

44. Murugan AT, Sharma G (2008) Obesity and respiratory diseases. Chron Respir Dis 5:233-242. https://doi.org/10.1177/1479972308 096978

45. Zheng KI, Gao F, Wang X-B, Sun Q-F, Pan K-H, Wang T-Y et al (2020) Letter to the Editor: obesity as a risk factor for greater severity of COVID-19 in patients with metabolic associated fatty liver disease. Metabolism 108:154244. https://doi.org/10.1016/j. metabol.2020.154244

46. Iacobellis G, Secchi F, Capitanio G, Basilico S, Schiaffino S, Boveri $S$ et al (2020) Epicardial Fat Inflammation in severe COVID-19. Obesity. https://doi.org/10.1002/oby.23019

47. Kass DA, Duggal P, Cingolani O (2020) Obesity could shift severe COVID-19 disease to younger ages. Lancet 395:1544-1545

48. Ryan PM, Caplice NM (2020) Is adipose tissue a reservoir for viral spread, immune activation, and cytokine amplification in coronavirus disease 2019? Obesity 28:1191-1194. https://doi.org/ $10.1002 /$ oby. 22843

49. Chiappetta S, Sharma AM, Bottino V, Stier C (2020) COVID-19 and the role of chronic inflammation in patients with obesity. Int $\mathrm{J}$ Obes 44:1790-1792. https://doi.org/10.1038/s41366-020-0597-4

50. Iacobellis G, Malavazos AE, Corsi MM (2011) Epicardial fat: From the biomolecular aspects to the clinical practice. Int J Biochem Cell Biol 43:1651-1654. https://doi.org/10.1016/j.biocel. 2011.09.006

51. Malavazos AE, Goldberger JJ, Iacobellis G (2020) Does epicardial fat contribute to COVID-19 myocardial inflammation? Eur Heart J 41:2333

52. Grodecki K, Lin A, Razipour A, Cadet S, McElhinney PA, Chan $\mathrm{C}$ et al (2021) Epicardial adipose tissue is associated with extent 
of pneumonia and adverse outcomes in patients with COVID-19. Metabolism 115:154436. https://doi.org/10.1016/j.metabol.2020. 154436

53. Chait A, den Hartigh LJ (2020) Adipose tissue distribution, inflammation and its metabolic consequences, including diabetes and cardiovascular disease. Front Cardiovasc Med 25(7):22. https://doi.org/10.3389/fcvm.2020.00022

54. Ruan Q, Yang K, Wang W, Jiang L, Song J (2020) Clinical predictors of mortality due to COVID-19 based on an analysis of data of 150 patients from Wuhan. China Intensive Care Med 46:846-848

55. Fontana L, Eagon JC, Trujillo ME, Scherer PE, Klein S (2007) Visceral fat adipokine secretion is associated with systemic inflammation in obese humans. Diabetes 56(4):1010-1013. https://doi.org/10.2337/db06-1656

56. Vieira-Potter VJ (2014) Inflammation and macrophage modulation in adipose tissues. Cell Microbiol 16(10):1484-1492. https://doi. org/10.1111/cmi.12336

57. Watanabe M, Risi R, Tuccinardi D, Baquero CJ, Manfrini S, Gnessi L (2020) Obesity and SARS-CoV-2: a population to safeguard. Diabetes Metab Res Rev. https://doi.org/10.1002/dmrr. 3325
58. Zhou F, Yu T, Du R et al (2020) Clinical course and risk factors for mortality of adult in patients with COVID-19 in Wuhan, China: a retrospective cohort study. Lancet 395(10229):1054-1062

59. Pagani S, Meazza C, Travaglino P, De Benedetti F, Tinelli C, Bozzola M (2005) Serum cytokine levels in GH-deficient children during substitutive GH therapy. Eur J Endocrinol 152:207-210

60. Snel YE, Brummer RJ, Doerga ME, Zelissen PM, Bakker CJ, Hendriks MJ, Koppeschaar HP (1995) Adipose tissue assessed by magnetic resonance imaging in growth hormone-deficient adults: the effect of growth hormone replacement and a comparison with control subjects. Am J Clin Nutr 61(6):1290-1294. https://doi.org/ 10.1093/ajen/61.6.1290

61. Lubrano C, Masi D, Risi R, Balena A, Watanabe M, Mariani S, Gnessi L (2020) Is growth hormone insufficiency the missing link between obesity, male gender, age, and COVID-19 severity? Obesity 28:2038-2039. https://doi.org/10.1002/oby.23000

Publisher's Note Springer Nature remains neutral with regard to jurisdictional claims in published maps and institutional affiliations.

\section{Authors and Affiliations}

\section{Alexis Elias Malavazos ${ }^{1}$ (1) . Francesco Secchi ${ }^{2,3}$. Sara Basilico ${ }^{1,4}$. Gloria Capitanio ${ }^{1}$. Sara Boveri ${ }^{5} \cdot$ Valentina Milani $^{5}$. Carola Dubini ${ }^{1}$. Simone Schiaffino ${ }^{2}$. Lelio Morricone ${ }^{1}$. Chiara Foschini ${ }^{2} \cdot$ Giulia Gobbo $^{6} \cdot$ Rosangela Piccinni $^{6}$. Alessandro Saibene ${ }^{7}$. Francesco Sardanelli $i^{2,3} \cdot$ Lorenzo Menicanti $^{5} \cdot$ Marco Guazzi $^{3,8}$. Chuanhui Dong ${ }^{9}$. Massimiliano Marco Corsi Romanelli ${ }^{3,10} \cdot$ Michele Carruba $^{11} \cdot$ Gianluca lacobellis ${ }^{12}$}

1 Endocrinology Unit, Clinical Nutrition and Cardiovascular Prevention Service, IRCCS Policlinico San Donato, Piazza Edmondo Malan 2, San Donato Milanese, 20097 Milan, Italy

2 Radiology Unit, IRCCS Policlinico San Donato, San Donato Milanese, Milan, Italy

3 Department of Biomedical Sciences for Health, Università Degli Studi Di Milano, Milan, Italy

4 School of Food Science, Università Degli Studi Di Milano, Milan, Italy

5 Scientific Directorate, IRCCS Policlinico San Donato, San Donato Milanese, Milan, Italy

6 General Medicine Unit, IRCCS Policlinico San Donato, San Donato Milanese, Milan, Italy

7 Department of General Medicine, Diabetes and Endocrinology, IRCCS Ospedale San Raffaele, Milan, Italy
8 Cardiology University Department, Heart Failure Unit, IRCCS Policlinico San Donato, San Donato Milanese, Milan, Italy

9 Department of Neurology, Leonard M. Miller School of Medicine, University of Miami, Coral Gables, FL, USA

10 Operative Unit of Laboratory Medicine1-Clinical Pathology, Department of Pathology and Laboratory Medicine, IRCCS Policlinico San Donato, San Donato Milanese, Milan, Italy

11 Department of Medical Biotechnology and Translational Medicine, Center for Study and Research On Obesity, University of Milan, Milan, Italy

12 Division of Endocrinology, Diabetes and Metabolism, Department of Medicine, University of Miami, Coral Gables, FL, USA 